\title{
Evaluation of anti-diabetic activity of Carica papaya leaves extract using yeast cells method
}

\author{
${ }^{1}$ Elhaj, R.A., ${ }^{2,3,{ }^{*}}$ Ya'akob, H. and ${ }^{2}$ Abd Malek, R. \\ ${ }^{1}$ Faculty of Science, Universiti Teknologi Malaysia, 81310, Johor Bahru, Johor, Malaysia \\ ${ }^{2}$ Institute of Bioproduct Development, Universiti Teknologi Malaysia, 81310, Johor Bahru, Johor, Malaysia \\ ${ }^{3}$ Faculty of Chemical and Energy Engineering, Universiti Teknologi Malaysia, 81310, Johor Bahru, Johor, \\ Malaysia
}

\begin{abstract}
Article history:
Received: 23 October 2019

Received in revised form: 16

February 2020

Accepted: 16 March 2020

Available Online: 15 April 2020
\end{abstract}

Keywords:

Anti-diabetic,

Carica papaya,

Yeast method,

Glucose uptake,

Diabetes mellitus

DOI:

https://doi.org/10.26656/fr.2017.4(S2).S01

\begin{abstract}
The present diabetes epidemic highlights the need for adequate and efficient drugs. The implementation of alternative and complementary medicinal products becomes a high priority. Many trials disclosed Carica papaya's anti-diabetic function, but its function in taking up glucose was not fully discovered. Therefore, this study aimed to evaluate the rate of glucose uptake across the cell membrane in the yeast cell system in the presence of C. papaya aqueous extract in different concentrations ( $1 \mathrm{mg}, 2 \mathrm{mg}, 3 \mathrm{mg}, 4 \mathrm{mg}, 5 \mathrm{mg}$ ) at different glucose concentrations $(5 \mathrm{mM}, 10 \mathrm{mM}, 25 \mathrm{mM})$. The results showed that a linear improvement in the transport of glucose a cross yeast was comparable to Metformin at different glucose concentrations. The maximum glucose uptake was $76 \%$ in $5 \mathrm{mg}$ of aqueous extract of $C$. papaya at $5 \mathrm{mM}$ glucose concentration. The finding of this study may be useful for future research and the development of a new natural product to treat diabetes mellitus.
\end{abstract}

\section{Introduction}

Diabetes mellitus (DM) is a disease that is often hereditary in nature but can be developed related to environment and habits. The global incidence of diabetes among adolescents will be a rise in 2030 by $69 \%$ in developing nations and by $20 \%$ in advanced nations (Shaw et al., 2010). Hyperglycaemia, which can influence other associated organs such as kidneys, eyes, and heart, characterizes it. This metabolic disorder has become one of the main causes of morbidity and mortality due to this broad spectrum of diabetic complications. (Abu Bakar et al., 2015). It is essential to clarify that diabetes is a heterogeneous group of diseases that have distinct pathophysiological mechanisms and therefore require different approaches to treatment.

Many anti-diabetic medicines like, alpha-glucosidase inhibitors, sulfonylurea and insulin derivatives are used to treat diabetes, there is no single drug used for a complete cure for this disease. Moreover, current drugs have several adverse effects, (Kendall et al., 2005; Joshi et al., 2015). The need for new diabetes therapies is predicted to grow dramatically over the next decade as a consequence of the worldwide epidemic of diabetes. For instance, researchers are focused on developing a safer and single diabetes remedy. Intensive studies were carried out to identify new therapeutic objectives and pharmacological compounds that could correct the impaired tolerance of glucose.

Saccharomyces cerevisiae is frequently known as baker's yeast. It is a unicellular organism that is often used in scientific research owing to the protein sequence and function similar to that observed in other organisms (Lagunas, 1979). Yeast cell offers a biological environment and the glucose uptake in yeast cell is one of the significant instruments for checking the antidiabetic potential of herbal medicine (Nair et al., 2013).

C. papaya is one of the major fruit crops cultivated in tropical and sub-tropical zones (Silva et al., 2007). Many published clinical evidence had shown the remedy role of papaya leaves in diabetes mellitus, but the mechanism role was not evident, (Juárez-Rojop et al., 2012; Juárez-Rojop et al., 2014; Miranda-Osorio et al., 2016). The current investigation was conducted to assess the possible mechanism of action of aqueous leaves extract of C. papaya using yeast method. 


\section{Materials and methods}

\subsection{Plant Material}

C. papaya leaves cultivar Eksotica were collected from the Malaysian Agriculture Research and Development Institute (MARDI), Selangor. The leaves were authenticated by the botanist and the specimens (SK 3143/17) were kept in the herbarium of the Institute of Bioscience, University Putra Malaysia, Serdang, Selangor, Malaysia.

\subsection{Chemical and Reagent}

Baker's yeast (Saccharomyces cerevisiae) strain number ATCC 69934, D-Glucose, metformin from Sigma Aldrich and 3-5 dinitrosalicyclic acid from QREC Asia. All the chemicals used in the study were of extra pure analytical grade

\subsection{Plant Extraction}

C. papaya leaves were cleaned, dried in an oven $\left(50^{\circ}\right.$ C) and then ground into a fine powder

Using the Waring blender. The leaves extract was prepared using the reflux method as described by (Aditha et al., 2016) and then filtered through Whatman No. 1 filter paper (Whatman Inc., Clifton, New Jersey). The extract was evaporated to dryness under vacuum at $50^{\circ} \mathrm{C}$ using rotary evaporator. The dry extract was stored at $20^{\circ} \mathrm{C}$ until further usage.

\subsection{In vitro evaluation of glucose uptake by yeast cells}

This study was conducted using the well-defined methods by (Cirillo, 1962) with altered modification. Commercial baker's yeast (Saccharomyces cerevisiae) was washed by repeated centrifugation at $3000 \mathrm{rpm}$ for 5 mins using distilled water until the supernatant fluids were clear and a $10 \%(\mathrm{v} / \mathrm{v})$ suspension was prepared in distilled water using 10 parts of the clear supernatant fluid and 90 parts of distilled water. Various

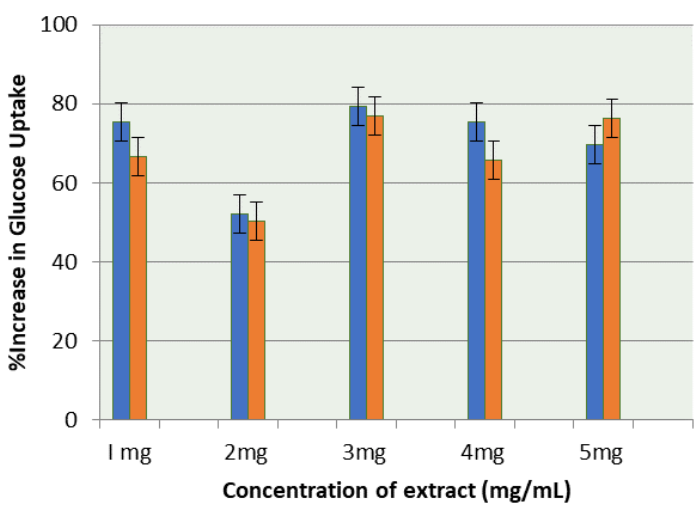

n standard

$\square$ aqueous

Figure 1. The comparative \% increase in glucose uptake by yeast cells due to the effect of aqueous extracts of C. papaya and reference Standard drug (Metformin) at $5 \mathrm{mM}$ Glucose Concentration (values are expressed as mean $\pm \mathrm{SE}, \mathrm{n}=3$ ) concentrations of aqueous extract $(1-5 \mathrm{mg} / \mathrm{mL})$ were added to $1 \mathrm{~mL}$ of glucose solution $(5,10$ and $25 \mathrm{mM})$ and further incubated for $10 \mathrm{mins}$ at $37^{\circ} \mathrm{C}$. The reaction began by adding $100 \mu \mathrm{L}$ of yeast suspension, vortex and further incubation at $37^{\circ} \mathrm{C}$ for 60 mins. After that, the tubes were centrifuged at 2,500 rpm for 5 mins) and glucose was estimated in the supernatant. Metformin was taken as a standard anti-diabetic drug. The percentage of increase in glucose uptake by yeast cells was calculated using the following formula:

Increase in glucose uptake $(\%)=\frac{\text { Abs control }- \text { Abs sample } \times 100}{\text { Abs sample }}$

Where Abs control is the absorbance of the control reaction (containing all reagents except the test sample) and Abs sample is the absorbance of the test sample. Absorbance was measured at $540 \mathrm{~nm}$ and all experiments were carried out in triplicates.

\subsection{Statistical analysis}

All experiments were performed in triplicates $(n=3)$ and the data are presented as the mean \pm standard error. Differences between the means of the individual groups were analyzed using the analysis of variance procedure of SPSS software 20 Version (IBM).

\section{Results}

The dried leaves of $C$. papaya were extracted using distilled water by reflux and the extract obtained having a yield value of $11.2 \% \mathrm{w} / \mathrm{w}$. The difference in glucose concentration in the medium after a specified period of time shows the glucose uptake by yeast cells. The current study's in vitro assays stated that the aqueous extract of C. papaya possesses good anti-diabetic activity. After the treatment of the yeast cells with the aqueous plant extract, the glucose uptake did not increase in a dosedependent manner. Figures 1,2,3 revealed the percentage increase in glucose uptake by yeast cell at different glucose concentrations $5 \mathrm{mM}, 10 \mathrm{mM}$ and $25 \mathrm{mM}$

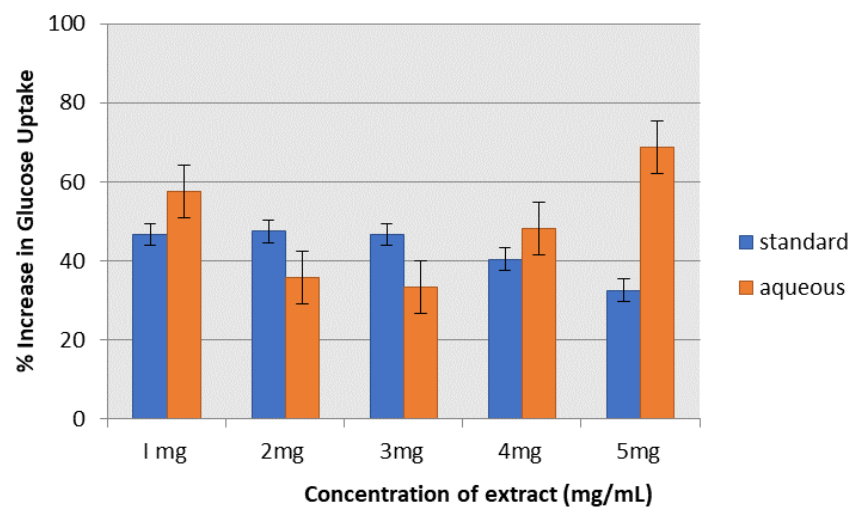

Figure 2. The comparative \% increase in glucose uptake by yeast cells due to the effect of aqueous extracts of $C$. papaya and reference Standard drug (Metformin) at 10mM Glucose Concentration (values are expressed as mean $\pm \mathrm{SE}, \mathrm{n}=3$ ) 


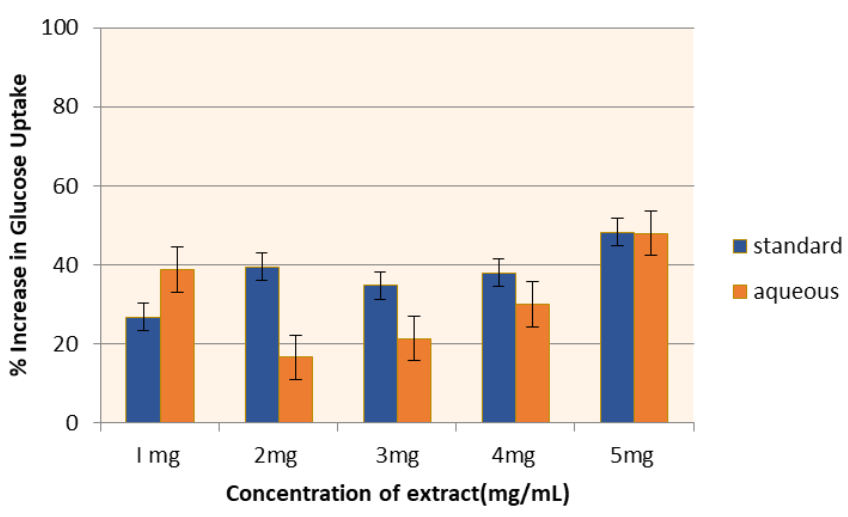

Figure 3. The comparative $\%$ increase in glucose uptake by yeast cells due to the effect of aqueous extracts of $C$. papaya and reference Standard drug (Metformin) at $25 \mathrm{mM}$ Glucose Concentration (values are expressed as mean $\pm \mathrm{SE}, \mathrm{n}=3$ )

respectively. The aqueous extract of $C$. papaya exhibited higher activity than standard drug metformin at $10 \mathrm{Mm}$ and $25 \mathrm{mM}$ glucose concentrations showing the maximum increase in $5 \mathrm{mM}$ Glucose concentration i.e. $76 \%$ increase at $5 \mathrm{mg} / \mathrm{mL}$ of plant extract (Figure 4 ).

\section{Discussion}

In reality, research on medicinal plants generally began with the extraction processes that play a vital part in the results of extraction, e.g. yields percentages and the quality of the phytochemicals generated. Reflux extraction is the most used procedure because of its efficacy and ease in use (Stalikas, 2007). As an in vitro screening technique for the hypoglycemic impact of respective compounds from medicinal plants, currently, the attention was focused more on the mechanism of in vitro glucose transport model. Glucose transport in $S$. cerevisiae depends on carrier-mediated, nonconcentrative facilitated diffusion. The budding yeast $S$. cerevisiae, like other human cells, prefers to consume the available glucose vigorously by enhancing glucose uptake through glucose transporters (Rolland et al., 2002). For all these reasons attention was paid to the mechanism of glucose transport across the yeast cell (Maier et al., 2002). The findings of this research indicated that $C$. papaya aqueous extract improved glucose uptake in yeast cells from $(0-67 \%)$ at different levels of glucose may be due to the plant extract. This scenario may be due to the plant extract could bind to glucose even at lower concentrations of glucose $(5 \mathrm{mM} /$ L) thereby reducing the amount of glucose available for transport across the intestinal lumen. A similar investigation was done by Bhutkar and Bhise (2013) stating that Albizzia lebbeck and Mucuna pruriens, both of them promoted glucose uptake through the yeast cells and the rate of uptake was linear.

Facilitated carriers are particular carriers that transport solutes down the gradient of concentration,

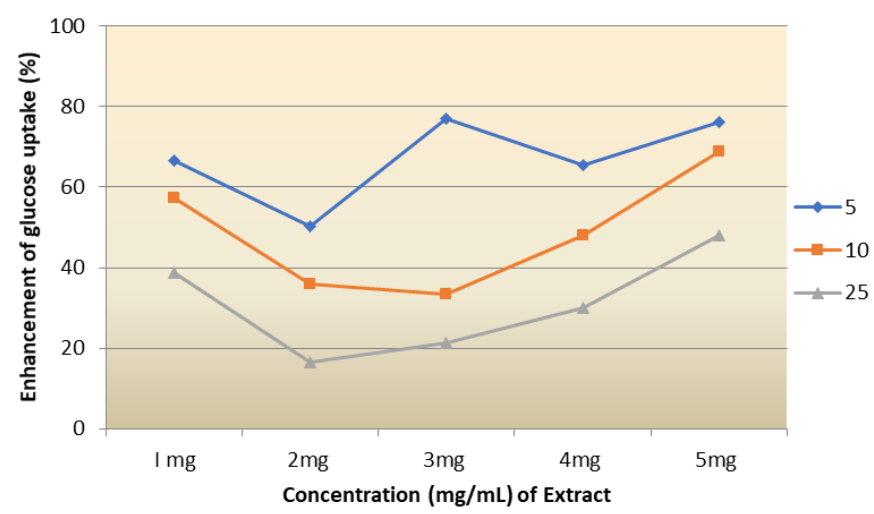

Figure 4. Effect of increasing concentration of C. papaya on the uptake of glucose by yeast cells in 5, 10, and $25 \mathrm{~m}$ Molar glucose concentration

emphasizing that efficient transport is achieved only when intracellular glucose is removed. Remarkably, in the present test, the increased ability of the samples to adsorb glucose may also be attributed to the dietary fibre (insoluble and soluble fibres) present in the sample similar observations have been reported by Chau et al. (2004) for insoluble fiber-rich fractions isolated from Averrhoa carambola. The yeast in vitro model assay offered rapid results in line with the agreement of present research.

\section{Conclusion}

The research encompasses the potential of the antidiabetic activity of $C$. papaya aqueous extract through the encouragement of yeast cell glucose uptake. Future experiments would use this in vitro yeast model as a form of screening natural extracts for its antidiabetic activity due to less time-intensive model compared to other in-vitro cell methods such as 3T3-L1 adipocytes or C2C12 myocytes that's need more time to prepare the cell line before application.

\section{Conflict of Interest}

The authors certify that they have no affiliation or interest in the subject matter or materials discussed in this manuscript.

\section{Acknowledgments}

This research was supported by the Ministry of Education and University Teknologi Malaysia for the grant scheme under High Centre of Excellence (vote number: RJI30000 7846. 4J261).

\section{References}

Abu Bakar, M.H., Sarmidi, M.R., Cheng, K.K., Ali Khan, A., Suan, C.L., Zaman, H.H. and Yaakob, H. (2015). Metabolomics - the complementary field in 
systems biology: A review on obesity and type 2 diabetes. Molecular BioSystems, 11(7), 1742-1774. https://doi.org/10.1039/C5MB00158G

Bhutkar, M. and Bhise, S. (2013). In vitro hypoglycemic effects of Albizzia lebbeck and Mucuna pruriens. Asian Pacific Journal of Tropical Biomedicine, 3 (11), 866-870. https://doi.org/10.1016/S2221-1691 (13)60170-7

Chau, C.F., Chen, C.H. and Lin, C.Y. (2004). Insoluble fiber-rich fractions derived from Averrhoa carambola: Hypoglycemic effects determined by in vitro methods. LWT-Food Science and Technology, 37(3), 331-335. https://doi.org/10.1016/ j.lwt.2003.10.001

Cirillo, V.P. (1962). Mechanism of glucose transport across the yeast cell membrane. Journal of Bacteriology, 84(3), 485-491. https:// doi.org/10.1128/JB.84.3.485-491.1962

Joshi, S.R., Standl, E., Tong, N., Shah, P., Kalra, S. and Rathod, R. (2015). Therapeutic potential of $\alpha$ glucosidase inhibitors in type 2 diabetes mellitus: An evidence-based review. Expert Opinion on Pharmacotherapy, 16(13), 1959-1981. https:// doi.org/10.1517/14656566.2015.1070827

Juárez-Rojop, I.E., Díaz-Zagoya, J.C., Ble-Castillo, J.L., Miranda-Osorio, P.H., Castell-Rodríguez, A.E., Tovilla-Zárate, C.A., Rodríguez-Hernández, A., Aguilar-Mariscal, H., Ramón-Frías, T. and Bermúdez-Ocaña, D.Y. (2012). Hypoglycemic effect of Carica papaya leaves in streptozotocin-induced diabetic rats. BMC Complementary and Alternative Medicine, 12(1), 236. https://doi.org/10.1186/14726882-12-236

Juárez-Rojop, I.E., Tovilla-Zárate, C.A., AguilarDomínguez D.E., Fuente, L.F.R.-D.L., LobatoGarcía, C.E., Blé-Castillo, J.L., López-Meraz, L., Díaz-Zagoya, J.C. and Bermúdez-Ocaña, D.Y. (2014). Phytochemical screening and hypoglycemic activity of Carica papaya leaf in streptozotocininduced diabetic rats. Revista Brasileira de Farmacognosia, 24(3), 341-347. https:// doi.org/10.1016/j.bjp.2014.07.012

Kendall, D.M., Riddle, M.C., Rosenstock, J., Zhuang, D., Kim, D.D., Fineman, M.S. and Baron, A.D. (2005). Effects of exenatide (exendin-4) on glycemic control over 30 weeks in patients with type 2 diabetes treated with metformin and a sulfonylurea. Diabetes Care, 28(5), 1083-1091. https:// doi.org/10.2337/diacare.28.5.1083

Lagunas, R. (1979). Energetic irrelevance of aerobiosis for $S$. cerevisiae growing on sugars. Molecular and Cellular Biochemistry, 27(3), 139-146. https:// doi.org/10.1007/BF00215362
Maier, A., Völker, B., Boles, E. and Fuhrmann, G.F. (2002). Characterisation of glucose transport in Saccharomyces cerevisiae with plasma membrane vesicles (countertransport) and intact cells (initial uptake) with single Hxt1, Hxt2, Hxt3, Hxt4, Hxt6, Hxt7 or Gal2 transporters. FEMS Yeast Research, 2 (4), 539-550. https://doi.org/10.1016/S1567-1356 (02)00140-X

Miranda-Osorio, P., Castell-Rodríguez, A., VargasMancilla, J., Tovilla-Zárate, C., Ble-Castillo, J., Aguilar-Domínguez, D., Juárez-Rojop, I. and DíazZagoya, J. (2016). Protective action of Carica papaya on $\beta$-cells in ctreptozotocin-induced diabetic rats. International Journal of Environmental Research and Public Health, 13(5), 446. https:// doi.org/10.3390/ijerph13050446

Nair, S.S., Kavrekar, V. and Mishra, A. (2013). In vitro studies on alpha amylase and alpha glucosidase inhibitory activities of selected plant extracts. European Journal of Experimental Biology, 3(1), 128-132.

Rolland, F., Winderickx, J. and Thevelein, J.M. (2002). Glucose-sensing and -signalling mechanisms in yeast. FEMS Yeast Research, 2(2), 183-201. https:// doi.org/10.1111/j.1567-1364.2002.tb00084.x

Shaw, J.E., Sicree, R.A. and Zimmet P.Z. (2010). Global estimates of the prevalence of diabetes for 2010 and 2030. Diabetes Research and Clinical Practice, 87 (1), 4-14. https://doi.org/10.1016/ j.diabres.2009.10.007

Silva, J.D., Rashid, Z., Nhut, D.T., Sivakumar, D., Gera, A., Souza, M.T. and Tennant, P. (2007). Papaya (Carica papaya L.) biology and biotechnology. Tree and Forestry Science and Biotechnology, 1(1), 4773.

Stalikas, C.D. (2007). Extraction, separation, and detection methods for phenolic acids and flavonoids. Journal of Separation Science, 30(18), 3268-3295. https://doi.org/10.1002/jssc.200700261 